\title{
TOURIST SATISFACTION: AN ANALYSIS OF PUSH AND PULL FACTORS - A CASE OF QATAR TOURISM
}

\author{
Swati Prasad \\ Head of Training and Development/Senior Lecturer, International Hospitality Management, \\ Stenden University of Applied Sciences - Qatar, Doha, QATAR \\ Girish.K.Nair* \\ Associate Professor \& Programme Leader, International Hospitality Management \\ Stenden University of Applied Sciences - Qatar, Doha, QATAR

\section{Harsh Purohit} \\ WISDOM, Faculty of Management Studies, anasthali University, Rajasthan, India \\ *corresponding author
}

\begin{abstract}
In the light of rising competition in providing tourism experience amongst Gulf Cooperation Council (GCC) and countries, how efficient Qatar has been in creating tourist satisfaction and tourist motivation in order to create tourist loyalty and promote tourism to global standards. Measuring tourist satisfaction plays an important role in marketing tourism products and services. The purpose of this study is to examine the push and pull factors of tourists visit; their motivation and the activities carry out at the destination. This study explore to understand what comprises tourists are satisfied to transmit their positive experience to third persons as well as repeating their visit to Qatar. The result was drawn from questionnaire survey of 494 international visitors who visited Qatar in 2018. The data were analyzed using matrices which shown the mean scores of expectations, the mean score of experience and the mean of difference between experience and expectation scores. The mean scores of expectation were then plotted against experience in a two dimensional map for positive and negative attributes. The t-test was performed to identify the significant result of each attributes at 1:1000 levels. The findings provide Qatar Tourism Authorities with insights about the level of satisfactions among international tourists and call for better improvements strategies for future tourism development in Qatar.
\end{abstract}

Keywords: Travel motivation; Push and Pull factors; Travel Destination; Qatar Cite this Article: Swati Prasad, Girish. K. Nair and Harsh Purohit, Tourist Satisfaction: an Analysis of Push and Pull Factors - A Case of Qatar Tourism, Journal of Management, 6 (2), 2019, pp. 187-199.

http://www.iaeme.com/JOM/issues.asp?JType=JOM\&VType=6\&IType=2 


\section{INTRODUCTION}

This research focusses on the issues related to tourism motivation in Qatar. Qatar is the highest Gross Domestic Product (GDP) earning country in the world with oil and gas as its main economy generating resources. Keeping in mind that oil and gas revenues won't support Qatar forever, the country has been working to diversify its economy to meet future needs. The main motivation for this research is the fact that Qatar has tourism development in its national vison of 2030 and is making every attempt to make the tourism experience in Qatar a world class experience. Qatar Tourism Authority (QTA) released 2017 Annual Tourism Statistics and announced that the tourism industry in Qatar continued to perform despite 23\% drop in tourist arrival as compared to 2016 at it was negatively affected by political developments in the region due to the Saudi-led blockade that was imposed on Qatar beginning in June. The report indicates continual growth and changes in its policy to attract tourist across the world.

Tourism represents an important part of a diversified Qatar economy. Tourism sector is in its early stages of development, and has directly contributed QR13.6 billion to GDP, representing $4 \%$ of non-extraction economy. As tourism industry thrives on repeat visits of tourists and increasing number of travellers mostly due to word of mouth, it's imperative at this stage to analyse the experience and psychology of tourist visiting Qatar. For the tourism industry tourist travel decision are very important to improve the status of tourism industry of travel destination. Papatheodorou, A. (2006) stated that travel decisions are the most important influencing factors to make a choice of travel destination.

In the present globalized scenario of tourism, the tourist satisfaction plays a major role in the success of the tourism industry. Qatar is promising tourist destinations in GCC with its very appealing motto, "All the Necessities of the Modern Home Under one Roof" which is now spread across the globe. But, there is a need to undertake a systematic study, applying management principles, to introduce the checks and balances in place to evaluate the performance standards of the service providers at different locations and stages of tourism to ensure that the tourists return with full satisfaction. So, the purpose of this research is to systematically study what constitutes tourist tourists satisfaction, their motivation and the activities carry out at their destination. This study explore to understand what comprises tourists are satisfied to transmit their positive experience to third persons as well as repeating their visit to Qatar so that an appropriate strategy may be developed to warrant that the service providers will fully meet the tourists' expectations and ultimately make Qatar one of the most sort after tourist destinations to any tourist in general.

\section{LITERATURE REVIEW}

\subsection{Tourist Motivation}

Concentrating on tourist motivation has always been a critical variable for tourism management. Caber and Albayrak (2016) state that conceptualisation of motivation originates from the consumer behaviour literature. Since motivation is the starting point of the consumer decision process and an important construct for understanding tourist behaviour, it became a widely investigated concept for many years by academics in the field of tourism and travel. Previous studies on tourist motivation can be divided into three categories. The majority of the first group have exploratory characteristics and focus on personal motivations that direct people towards specific behaviours. In the second group, motivation is used for market segmentation purposes. The third group of studies investigates the relationships amongst motivation and other constructs such as customer satisfaction and behavioural intention. Watthanaklang D. et.al. (2016) mentions that motivation is the force that drives individuals to serve their need to achieve a goal. In tourism, motivation is accepted as a crucial variable that explains tourism behaviour, 
and it is employed to assist in reasoning with respect to decision making, which enhances the identification of tourists' needs and their promotion to meet the needs of target groups. It is therefore important for tourism products such as resorts to understand the travel behaviour and more specific the travel motivations of tourists, as it may assist in product development, improved marketing strategies, enhanced service delivery approaches and the creation of a competitive advantage. Therefore, travel behaviour plays an important role in tourism as concept, industry and economy, and demands investigation Van Vuuren, C. \& Slabbert, E. (2011).

Various researchers have identified factors influencing travel behaviour of tourists such as variables motivating the tourist to travel, attitude of the tourist, various situational factors and environmental factors which influence the personal significance of the tourist (Venkatesh, 2006; Laws, 1995). According to March and Woodside (2005) travel motivations can be considered as one of the most important psychological influences of tourist behaviour.

\subsection{Push and Pull Factors in Tourism}

Bideci, M. \& Albayrak, T. (2016), identify that in tourism and travel literature, motivation is frequently used to understand tourist behaviour such as destination and activity selection. Differing needs and expectations of tourists lead to dramatic variations in demand in the tourism sector. Thus, motivation theories in the field of tourism are used as a tool for the identification of tourist needs as well. There are two groups of tourist motivations for travelling into two categories: 'willingness to see unknown and different cultures' and 'desire to travel for better conditions'. The push and pull factors that motivate people to travel. Lam, T. \& Hsu, C.H.C. (2006). While push factors are the inner impulses that lead people to travel, pull factors are destination features that meet their needs and expectations. Among the many theoretical constructs that measure motivation are Maslow's hierarchy of needs, Alderfer's ERG theory, Herzberg's motivator-hygiene theory, Pearce's leisure ladder, Iso-Ahola's escape-seeking dichotomy, and push and pull factors. Despite differences in these theories, all agree that the study of motivation is based on human psychological and biological needs. Understanding motivation can therefore help to advance the understanding of why tourists travel and what they want to enjoy. Leong, A.M.W., Yeh, S.S., Hsiao, Y.C., Huan, T.C. (2015) add that motivation is proved to be a moderator for the relationship between tourist expectation and attitude, between experiences and brand image formation, and between price and distance, and destination choice.

In tourism destination management, enhancing tourists' satisfaction levels and return intention are extremely crucial and necessary. A number of previous conceptual and empirical studies found that travel motivation, including internal or psychological forces (push factor) and external forces of the destination attributes (pull factor), is the fundamental reason to explain a particular traveling behavior of tourists, Mai Ngoc Khuong and Huynh Thi Thu Ha, (2014) the causal relationship among tourists' motivation, satisfaction and post-purchase intention, as well as confirming the vital role of understanding travel motivation in order to enhance their satisfaction and return intention.

Motivation commonly related to Push-pull factors that affects visitors' behavior. Push factors is a socio psychological visitor contract that effects on their motivation to visit an attraction and destination (peaceful, loneliness, to feel a new experience, etc). While the pull factors are the quality of the setting that attracts them to come to an attraction or specific destination. Beh, A., \& Bruyere, B.L. (2007). In choosing the destination, the tourists tend to classify their alternative choice based on several criteria, such as self-motivation (push factor), the domination perception of tourist from one destination (pull factor), and the available time and money (situational constraints). Motivation as push factor could be seen from four main 
groups that is environment or climate, relaxation, adventure and personal. On the other hand, perception as pull factor could be seen from visitor satisfaction components C.N.Lai, Yu, T.K., and J.K. Kuo,

\subsection{Push and Pull Factors impacting Tourist Motivation}

Deichmann, J.I. \& Frempong, F. (2016) set forth that travel motivation is an important consideration in evaluating whether tourists' expectations are fulfilled. Studies on travel demand often look at characteristics of travellers rather than the places they visit. For example, within the group motivated by pleasure travel a typology of 'wanderlust' travellers versus 'sunlust' travellers. Wanderlust tourists are driven to interact with different peoples and cultures, and this typically requires international travel. In contrast, sun lust tourists seek rest and relaxation, which can often be found at resorts offering the three Ss: sun, sand, and sea. In short, it is based mainly upon the purpose or motivation for a given trip. Similarly, the author distinguishes between 'allocentrics' and psychocentrics'. The former are motivated by exotic places and higher-risk experiences, while the latter tend to vacation closer to home. Such sociopsychological characteristics of tourists can be seen as push factors. The authors find that different psychographic population segments hold distinct tendencies to travel domestically or overseas. Reporting from survey results of British and German tourists, the authors discover that climate, sea, and scenery represent chief motivations for travel. Social contacts and travel prices are found to be significant reasons for British travellers to remain in their home country Adel H. Nikjoo \& Mahmoud Ketabi (2015)

Šimková, E. \& Holzner, J. (2014) for tourist classification can be used Plog's psychographic motivation theory. This theory classifies tourists along their personal characteristics, life-style and personal values, to psychocentrics at one extreme to the allocentrics at the other. Psychocentrics are represented by people concerned on their own affairs, i.e. non adventurous visitors, who often require standard services, while allocentrics are independent tourists seeking for adventure or experience. Between these two extremes are mid centrics. Midcentrics actually represent majority of tourists, and these are people who occupy borders with near psychocentrics and near allocentrics. These are tourists relatively flexible in their needs. As already mentioned, tourists in rural areas require authentic pristine rural locality with "romantic" and "traditional" life. On the other hand they are usually easy going people, who value low prices for products, or seek activities outside in beautiful landscapes and nature Lam, T. \& Hsu, C.H.C. (2006). . Study presents several similarities for rural tourists: they are motivated by opportunities to explore nature, participate in outdoor activities, and search for peace and quiet, family atmosphere.

Baby boomers can be defined as a cohort of individuals born between the years 1946 and 1964. They are now aged between 50 and 68 years. The Baby Boomers Summit held in 2009 labelled this generation as 'The Recession Boosters' as they have the ability to recover from the economic crisis. Moreover most of them are healthy, have more disposable income, are better educated and have more leisure time and reduced family obligations. Business operators are becoming increasingly aware of the economic potential of the baby boomers' segment and recognise that these travellers will account for a larger share of the tourism industry. Therefore, due to global aging patterns and its economic potentials, tourism practitioners are required to further understand the needs and motivations of this segment Naidoo,P., Munhurrun,P.R., Seebaluck, N.V. \& Janvier, S. (2015).

The tourist motivation provides the evidence by explaining the reason or the motive of sightseeing that connects to satisfying the tourist's desire. The tourist motivation appears differently according to the individual, mental, and internal environments of the tourist and external factors such as the cultural, environmental, and periodical environments. Since tourist 
motivation derives from internal factors of the tourist himself and the characteristics of the tourist site, observing push factors and pull factors is important. Whang, H. Yong, S. \& Ko, E. (2016)

\section{METHODOLOGY}

\subsection{Respondents of the research}

The target population of the study is that tourist who visited Qatar during the year 2018-2019. The questionnaire was circulated among 630 respondents. However, out of 630 questionnaires, 101 candidates did not reply, 35 questionnaires were received back as incomplete and hence could not be incorporated in the analysis. The analysis is conducted on 494 completed questionnaire received by the researcher.

\subsection{Questionnaire}

The first section if the questionnaire is intended to understand the demographics of the sample. This consists of various multiple choice questions which are planned to categorize the sample. A random sample has been chosen from this population with proportional grouping by country of origin, demographics, age, purpose of visit etc.

\subsection{Demographics of sample}

Vast majorities of population under study is young population of age 18-24 years and are travelling in groups of more than 5 people. Though the population under study comprises of citizens of various countries like Australia, Berlin and Rome, Denmark, France, Germany, Netherlands, India, New Zealand, Philippines, Sri Lanka, Sweden, UAE, UK but about $50 \%$ of the respondents are German citizen. Qatar is a popular among the population under study primarily for reasons like education, visiting friends or family, and business for an average of 5-10 days. The population under study has indicated that they have primarily stayed with their family and friends or apartments.

\subsection{Sample distribution}

The first question seeks to understand if the respondent is visiting Qatar for the first time or has been to the country before. The data collected indicates that about $75 \%$ of the respondents are visiting Qatar for the first time whereas about $25 \%$ of the respondents have visited the country before. Out of $25 \%$ of the respondents who have visited the country before, $41 \%$ of the respondents have visited the country before 1 to 2 times, $7 \%$ have visited the country 3 to 4 times while about $50 \%$ of the people have visited the country more than 5 times. These people usually travel to Qatar for business purposes. About 54\% of sample population is travelling with friends while $28 \%$ is travelling with family. Another $11 \%$ is travelling alone and $7 \%$ is travelling with partner.

\subsection{Method of data collection}

This section of the questionnaire discusses the presence of the tourist destination elements in Qatar. These elements have been shortlisted after a thorough review of literature. The respondents were asked to indicate on a scale of $1-5$ to what extent do they agree with the statement that these elements are HIGH or LOW at this tourist destination (where $» 1 \ll$ means Exceptionally low, »5« - Exceptionally High). 


\subsection{Identify of factors and indicators}

Table 1 Factors and Indicators of Push and Pull Tourist Visit to Qatar

\begin{tabular}{|c|c|c|c|}
\hline & Mean & Std. & Analysis \\
& & Deviation & N \\
\hline Personal safety and security & 4.01 & .830 & 494 \\
\hline The destination has strong connectivity & 3.29 & 1.086 & 494 \\
\hline Overall cleanliness of the destination & 4.03 & .853 & 494 \\
\hline Climate conditions & 3.12 & .869 & 494 \\
\hline and customs) & 3.42 & 1.037 & 494 \\
\hline Diversity of cultural/historical attractions (architecture, tradition & 3.87 & .783 & 494 \\
\hline The quality of the accommodation (hotel, motel, apartment) & 3.57 & 1.034 & 494 \\
\hline Friendliness of the local people & 2.62 & 1.093 & 494 \\
\hline Organization of the local transportation services & 3.56 & .984 & 494 \\
\hline The offer of local cuisine & 4.13 & .943 & 494 \\
\hline Possibilities for shopping & 3.20 & .969 & 494 \\
\hline Night life and entertainment & 3.66 & .846 & 494 \\
\hline Opportunity for rest & 3.52 & .963 & 494 \\
\hline Availability of sport facilities and recreational activities & 3.35 & .855 & 494 \\
\hline Offer of cultural and other events & 3.47 & .822 & 494 \\
\hline Spa and Wellness & 2.27 & 1.093 & 494 \\
\hline Availability of casino and gambling & 3.27 & .912 & 494 \\
\hline Organization of Conference & 3.44 & .748 & 494 \\
\hline
\end{tabular}

\subsection{Method of Data Analysis}

The researcher uses Principal Component Method for factor analysis.

Let $X_{i}$ be a vector of observations for the $i^{t h}$ subject:

$$
\begin{gathered}
X_{i}=\left(\begin{array}{c}
X_{1 i} \\
X_{2 i} \\
\vdots \\
X_{i p}
\end{array}\right) \\
S=\frac{1}{n-1} \sum_{i=1}^{n}\left(X_{i}-x^{-}\right)\left(X_{i}-x^{-}\right)^{\prime}
\end{gathered}
$$

Where $\mathrm{S}$ denotes sample variance-covariance matrix.

We have $p$ eigenvalues for this variance-covariance matrix as well as corresponding eigenvectors for this matrix.

Eigenvalues of $\mathbf{S}: \wedge \lambda 1, \wedge \lambda 2, \ldots, \wedge \lambda p \lambda^{\wedge} 1, \lambda^{\wedge} 2, \ldots, \lambda^{\wedge} \mathrm{p}$

Eigenvectors of $\mathbf{S}: \wedge \mathrm{e} 1, \wedge \mathrm{e} 2, \ldots, \wedge \mathrm{ep}$

Re expressing variance-covariance matrix can be in the following form as a function of the eigenvalues and the eigenvectors: 


$$
\sum=\sum_{i=1}^{p} \lambda_{i} e_{i} e_{i}^{\prime} \cong \sum_{i=1}^{m} \lambda_{i} e_{i} e_{i}^{\prime}=\left(\sqrt{\lambda_{i} e_{1}}\right)\left(\sqrt{\lambda_{i} e_{2}}\right) \ldots \ldots\left(\sqrt{\lambda_{i} e_{i}}\right)\left(\begin{array}{c}
\sqrt{\lambda_{i}} e_{1} \\
\sqrt{\lambda_{i} e_{2}} \\
\vdots \\
\sqrt{\lambda_{i} e_{i}}
\end{array}\right)=L L^{\prime}
$$

The idea behind the principal component method is to approximate this expression. Instead of summing from 1 to $p$, we now sum from 1 to $m$, ignoring the last $p-m$ terms in the sum and obtain the third expression.

\section{RESULTS}

\subsection{Fit of model}

KMO and Bartlett's Test is used to determine the suitability of the data for factor analysis. The test indicates the proportion of variance in the variables under study that might be caused by factors under study. A KMO value between 0.8 and 1 signify that the sample is adequate for factor analysis and it will provide significant results. The KMO value of 0.822 for the sample indicates that factor analysis can be done on the data.

Table 2 Factors and indicators of Push and Pull tourist visit to Qatar

\begin{tabular}{|c|c|c|c|c|}
\hline & $\begin{array}{c}\text { Scale Mean } \\
\text { if Item } \\
\text { Deleted }\end{array}$ & $\begin{array}{c}\text { Scale } \\
\text { Variance } \\
\text { if Item } \\
\text { Deleted } \\
\end{array}$ & $\begin{array}{c}\text { Corrected } \\
\text { Item- } \\
\text { Total } \\
\text { Correlation } \\
\end{array}$ & $\begin{array}{c}\text { Cronbach's } \\
\text { Alpha } \\
\text { if Item } \\
\text { Deleted } \\
\end{array}$ \\
\hline Personal safety and security & 57.77 & 56.485 & .314 & .779 \\
\hline The destination has strong connectivity & 58.49 & 50.530 & .608 & .756 \\
\hline Overall cleanliness of the destination & 57.75 & 55.069 & .419 & .773 \\
\hline Climate conditions & 58.66 & 57.283 & .232 & .785 \\
\hline $\begin{array}{l}\text { Diversity of cultural/historical attractions } \\
\text { (architecture, tradition and customs) }\end{array}$ & 58.36 & 54.175 & .383 & .775 \\
\hline $\begin{array}{l}\text { The quality of the accommodation (hotel, motel, } \\
\text { apartment) }\end{array}$ & 57.91 & 58.090 & .201 & .786 \\
\hline Friendliness of the local people & 58.22 & 55.517 & .293 & .782 \\
\hline Organization of the local transportation services & 59.17 & 56.822 & .187 & .791 \\
\hline The offer of local cuisine & 58.22 & 56.413 & .251 & .784 \\
\hline Possibilities for shopping & 57.66 & 53.491 & .487 & .768 \\
\hline Night life and entertainment & 58.58 & 54.982 & .360 & .777 \\
\hline Opportunity for rest & 58.13 & 52.958 & .603 & .761 \\
\hline $\begin{array}{l}\text { Availability of sport facilities and recreational } \\
\text { activities }\end{array}$ & 58.27 & 52.118 & .579 & .761 \\
\hline Offer of cultural and other events & 58.44 & 53.382 & .559 & .764 \\
\hline Spa and Wellness & 58.32 & 55.102 & .436 & .772 \\
\hline Availability of casino and gambling & 59.52 & 58.108 & .108 & .797 \\
\hline Organization of Conference & 58.51 & 56.405 & .282 & .782 \\
\hline $\begin{array}{l}\text { Availability of sufficient information about the } \\
\text { destination }\end{array}$ & 58.34 & 56.392 & .369 & .777 \\
\hline
\end{tabular}

\subsection{Reliability test}

The study uses Cronbach's Alpha as a measure of internal consistency; that is, to know all items contained within the instrument quantify the same general construct or not. The value of Alpha typically varies between 0 and 1 . The nearer the value of alpha to 1 , the greater the internal 
consistency of items in the instruments. The reliability test was applied on the data and the value of cronbach's Alpha is derived as 0.862 as shown in table below which is more than 0.7 .

Table 3 Reliability test

\begin{tabular}{|c|c|c|c|c|c|c|c|c|c|}
\hline \multirow{2}{*}{$\#$} & \multicolumn{3}{|c|}{ Initial Eigenvalues } & \multicolumn{3}{|c|}{ Extraction Sums of Squared Loadings } & \multicolumn{3}{|c|}{$\begin{array}{c}\text { Rotation Sums of Squared } \\
\text { Loadings }\end{array}$} \\
\cline { 2 - 11 } & Total & $\begin{array}{c}\% \text { of } \\
\text { Variance }\end{array}$ & $\begin{array}{c}\text { Cumulative } \\
\%\end{array}$ & Total & $\begin{array}{c}\% \text { of } \\
\text { Variance }\end{array}$ & $\begin{array}{c}\text { Cumulative } \\
\%\end{array}$ & Total & $\begin{array}{c}\% \text { of } \\
\text { Variance }\end{array}$ & $\begin{array}{c}\text { Cumulativ } \\
\mathrm{e} \%\end{array}$ \\
\hline 1 & 4.419 & 24.548 & 24.548 & 5.801 & 32.228 & 32.228 & 3.542 & 19.679 & 19.679 \\
\hline 2 & 2.735 & 15.194 & 39.742 & 1.940 & 10.776 & 43.004 & 2.301 & 12.781 & 32.461 \\
\hline 3 & 1.760 & 9.777 & 49.519 & 1.507 & 8.374 & 51.378 & 2.236 & 12.423 & 44.884 \\
\hline 4 & 1.510 & 8.387 & 57.907 & 1.305 & 7.251 & 58.629 & 1.800 & 10.001 & 54.885 \\
\hline 5 & 1.220 & 6.777 & 64.684 & 1.228 & 6.820 & 65.449 & 1.764 & 9.799 & 64.684 \\
\hline
\end{tabular}

Eigenvalue of Pull factors components the tourists visit to Qatar

Note: Extraction Method: Principal Component Analysis.

Five factors by the eigen value explaining 64.684 percent of the total variance which can be seen in table. It is clear from the table that out of 18 original variables factors with eigen value more than 1 has been extracted. These five factors account for 64.684 percent of cumulative variance. It means more than 60 percent information is retained and only 35.316 percent information is lost.

Table 4 Extracted Determinants of Pull factors the tourist to visit Qatar

\begin{tabular}{|c|c|c|c|c|c|c|c|}
\hline & \multirow[b]{2}{*}{ Factor } & \multicolumn{3}{|c|}{$\begin{array}{c}\text { Extraction Sums of Squared } \\
\text { Loadings }\end{array}$} & \multicolumn{3}{|c|}{$\begin{array}{c}\text { Rotation Sums of Squared } \\
\text { Loadings }\end{array}$} \\
\hline & & Total & $\begin{array}{c}\% \text { of } \\
\text { Variance }\end{array}$ & $\underset{\%}{\text { Cumulative }}$ & Total & $\begin{array}{c}\% \text { of } \\
\text { Variance }\end{array}$ & $\begin{array}{c}\text { Cumulative } \\
\%\end{array}$ \\
\hline 1 & Recreation Facilities & 5.801 & 32.228 & 32.228 & 3.542 & 19.679 & 19.679 \\
\hline 2 & Hospitality Services & 1.94 & 10.776 & 43.004 & 2.301 & 12.781 & 32.461 \\
\hline 3 & $\begin{array}{l}\text { Special Cultural } \\
\text { Attractions }\end{array}$ & 1.507 & 8.374 & 51.378 & 2.236 & 12.423 & 44.884 \\
\hline 4 & $\begin{array}{l}\text { Other Services at } \\
\text { Destination }\end{array}$ & 1.305 & 7.251 & 58.629 & 1.8 & 10.001 & 54.885 \\
\hline 5 & Local Factors & 1.228 & 6.82 & 65.449 & 1.764 & 9.799 & 64.684 \\
\hline
\end{tabular}

The local factors have the next highest mean $(M=14.28)$. The variable with the highest mean in the factor is overall cleanliness of the destination $(\mathrm{M}=4.03, \mathrm{SD}=0.85)$. The variable with the lowest mean is climate conditions $(\mathrm{M}=3.12, \mathrm{SD}=0.86)$. The hospitality services have the third highest mean $(M=13.78)$. The variable with highest mean is personal safety and security $(\mathrm{M}=4.01, \mathrm{SD}=0.83)$. The variable with lowest mean is organization of local transportation services $(\mathrm{M}=2.6, \mathrm{SD}=1.09)$. The factor about special cultural attractions at the destination has the next highest mean $(M=6.7)$. The variable with highest mean is diversity of cultural/ historical attractions $(\mathrm{M}=3.4, \mathrm{SD}=1.03)$. The variable with lowest mean is offer of cultural and other events $(\mathrm{M}=3.3, \mathrm{SD}=0.85)$. The factor with lowest mean is other services at the destination $(M=5.5)$. The variable with highest mean is organization of the conference $(M=$ 
$3.2, \mathrm{SD}=0.91)$ and the variable with lowest mean is availability of casino and gambling services $(\mathrm{M}=2.2, \mathrm{SD}=1.09)$.

Table 5 Eigenvalue of Push factors components the tourists visit to Qatar

\begin{tabular}{|l|l|l|l|l|l|l|l|l|l|}
\hline & \multicolumn{3}{|c|}{ Initial Eigenvalues } & \multicolumn{3}{c|}{ traction Sums of Squared Loadings } & \multicolumn{3}{|c|}{ Rotation Sums of Squared } \\
\cline { 2 - 10 } & Total & f Variance & mulative \% & Total & of Variance & mulative \% & Total & $\begin{array}{l}\text { \% of } \\
\text { Variance }\end{array}$ & $\begin{array}{c}\text { mulative } \\
\%\end{array}$ \\
\hline 56 & 448 & 448 & 56 & 448 & 448 & 42 & 249 & 249 \\
\hline 57 & 922 & 370 & 57 & 922 & 370 & 21 & 180 & 429 \\
\hline 46 & 20 & 291 & 46 & 20 & 291 & 12 & 070 & 499 \\
\hline 73 & 87 & 778 & 73 & 87 & 778 & 95 & 72 & 471 \\
\hline 99 & 67 & 245 & 99 & 67 & 245 & 62 & 74 & 245 \\
\hline
\end{tabular}

Note: Extraction Method: Principal Component Analysis.

Five factors have been indicated by the eigen value explaining 67.245 percent of the total variance which can be seen in table. It is clear from the table that out of 17 original variables factors with eigen value more than 1 has been extracted. These five factors account for 67.245 percent of cumulative variance. It means more than 60 percent information is retained and only 32.755 percent information is lost.

Table 6 Extracted Determinants of Push Factors the Tourist to visit Qatar

\begin{tabular}{|c|c|c|c|c|c|c|c|}
\hline \multirow{2}{*}{} & \multirow{2}{*}{ Factor } & \multicolumn{3}{|c|}{$\begin{array}{c}\text { Extraction Sums of Squared } \\
\text { Loadings }\end{array}$} & \multicolumn{3}{c|}{$\begin{array}{c}\text { Rotation Sums of Squared } \\
\text { Loadings }\end{array}$} \\
\cline { 2 - 8 } & & Total & $\begin{array}{c}\% \text { of } \\
\text { Variance }\end{array}$ & Cumulative $\%$ & Total & $\begin{array}{c}\% \text { of } \\
\text { Variance }\end{array}$ & $\begin{array}{c}\text { Cumulative } \\
\%\end{array}$ \\
\hline 1 & Tourist Leisure Facilities & 5.856 & 34.448 & 34.448 & 3.442 & 20.249 & 20.249 \\
\hline 2 & Connectivity & 1.857 & 10.922 & 45.370 & 2.921 & 17.180 & 37.429 \\
\hline 3 & Weather & 1.346 & 7.920 & 53.291 & 1.712 & 10.070 & 47.499 \\
\hline 4 & Shopping Experience & 1.273 & 7.487 & 60.778 & 1.695 & 9.972 & 57.471 \\
\hline 5 & Local Hospitality & 1.099 & 6.467 & 67.245 & 1.662 & 9.774 & 67.245 \\
\hline
\end{tabular}

The second factor 'Connectivity' has the highest mean $(\mathrm{M}=16.72)$. The variable with highest mean in the factor is maintenance and convenience of the airport $\mathrm{g}(\mathrm{M}=4.16, \mathrm{SD}=$ 0.95). The variable with lowest mean is convenience and access to local transport $(\mathrm{M}=2.2, \mathrm{SD}=$ 1.31). The recreational facilities have the next highest mean $(M=15.12)$. The variable with the highest mean in the factor is accessibility to cultural heritage sites $(M=3.14, \mathrm{SD}=1.38)$. The variable with the lowest mean is equipment for athletic activities $(\mathrm{M}=2.91, \mathrm{SD}=1.15)$. The local hospitality services have the third highest mean $(\mathrm{M}=13.81, \mathrm{SD}=4.88)$. The variable with highest mean is organized excursions $(\mathrm{M}=3.7, \mathrm{SD}=1.03)$. The variable with lowest mean is explanation and convenience of the customs $(\mathrm{M}=3.18, \mathrm{SD}=1.29)$. The factor about shopping experience at the destination has the next highest mean $(\mathrm{M}=7.8, \mathrm{SD}=2.04)$. The variable with highest mean is Shopping opportunities $(\mathrm{M}=4.18, \mathrm{SD}=0.83)$. The variable with lowest mean is degree of knowledge of foreign languages from the service personnel $(\mathrm{M}=3.7, \mathrm{SD}=1.21)$. The factor with lowest mean is weather conditions at the destination $(\mathrm{M}=3.22, \mathrm{SD}=1.37)$. 


\section{DISCUSSION}

The tourist leisure and recreational facilities are the strongest motivations to travel to Qatar. The factor consists of six variables namely possibilities for shopping, Availability of sport facilities and recreational activities, Night life and entertainment, Opportunity for rest and Spa and Wellness facilities. The next motivational factor is the local attractions. This includes four variables, such as overall cleanliness of the destination, friendliness of the local people, availability of sufficient information about the destination and climate conditions. The other factor is hospitality services. The factor includes four variables namely, the strong connectivity of destination, the quality of the accommodation (hotel, motel, apartment), organization of the local transportation services and personal safety and security of the tourists. The following factor is about special cultural attractions. The factor includes two variables, namely diversity of cultural/historical attractions (architecture, tradition and customs) and offer of cultural and other events. The weakest factor is the availability of other services at destination. It comprises of two variables, including facility for organization of conference and availability of casino and gambling.

Qatar is a popular among the population under study primarily for reasons like education, visiting friends or family, and business for an average of 5-10 days. On further enquiring if the respondents would like to visit the country again in next five years, the data collected indicates that $48 \%$ of the respondents have indicated that they would love to come back to the country. While another $32 \%$ of the respondents are not very sure about their choices, only $20 \%$ of the respondents have indicated that they might not visit the country again. Moreover, $42 \%$ of the respondents have indicated that they are completely satisfied with their trip to Qatar while 32\% of the respondents are highly satisfied and $23 \%$ of the respondents are partly satisfied with their trip. Less than $2 \%$ of the respondents are not satisfied with their trip to Qatar. Keeping the stated statistics in mind, it can be concluded that the tourists are motivated to visit Qatar again.

The data collected during the course of this research has indicated that the respondents of the questionnaire have visited the country for a variety of reasons including leisure $(10 \%$ of respondents), businessactivities (13\% of the respondents), visiting friends and relatives (17\% of respondents), for educational purposes and short-term course (less than 1 year) (21\% of the respondents), for short term volunteerism (less than 1 year) (about $1 \%$ of the respondents), for sports purposes (6\% of the respondents) and for other purposes like tour concerts, choir programs, students exchange programs, etc. (32\% of the respondents). It can be concluded that while educational activities are the most motivating activities for the tourist to plan their trip to Qatar, leisure activities are the second in the list.

\section{RECOMMENDATIONS}

Though Qatar has a wide bouquet of various sports opportunities to the tourists they expected the sports arenas to be a little more athletic friendly and also have some training facilities. It is therefore recommended that with sports arenas, some training facilities should be developed with small short term training programs which can attract tourists. These programs need to be advertised strongly to attract the attention of the tourists. They also need to be carefully planned so that they can attract people throughout the world.

The tourism authorities should plan and encourage development of supervised childcare such as a kids' club. They should include planning of some interactive sessions which should not only include fun activities but also development activities. They should be able to justify the number of children that are cared for. Groups should be split according to age and provision should also be made for children which special needs. Absence of such facilities sometimes leads to cancelation of plans and look for alternatives. Special sports facilities should also be 
developed for children of all ages along with open play ground in almost every locality for the children to play freely.

Due to blockade, the route to and from Qatar is impacted. There is increase in travel time in some cases, increase in fare in other cases or even a situation of no direct flights to Qatar due to blockade. Some of the respondents who have previously visited Qatar in the times when there was no such blockade indicated that they miss the easy connectivity of Qatar. Hence, the Government of Qatar should try to negotiate the connectivity of flights to or from Qatar or use of the airspace by airlines operating routes to Qatar. The problem of connectivity has a strong impact on the tourism in the country and should be resolved as soon as possible. The Qatar airways should also think of budget airlines for budget conscious travelers. Qatar Airways is branded as luxury airlines with expensive tickets. They can think of collaborating with some of the budget airlines to please the customers who are mindful of budget issues.

Another arena which needs some improvements is regarding local transportation in Qatar. The country has a rapidly expanding bus system but the system is confusing. The busses are little irregular and accurate information about the busses is also difficult to find. A little help and effort in this direction can go a long way to make local transportation efficient and more useful for the travelers. Though the country has a strong taxi system, securing taxi can be difficult at peak hours. This increases the reliability on bus services. The government needs review its bus infrastructure. The respondents of the research also reported that though some stops provide seating, maps, schedules and signs that show the time of the next arrival and other useful information' other stops have nothing more than a small sign on a lamp pole and involve long waits in the heat, leaving a feeling of uncertainty about whether the passenger is in the right place or not. A good proportion of tourists complain that they cannot always afford taxi therefore a good public transportation system should be developed.

The country is home to various museums, galleries, public art auditoriums, cultural village and various historic sites. Though the country has a rich cultural, the respondents of the survey conducted for this research have indicated that they did not understand the customs very well or they did not understand the customs at all. The culture of Qatar is very different from many of the western cultures. This fact calls for some investments concerning familiarizing the tourists towards the culture of the country. This can involve organizing cultural exchange programs, organizing international film festivals based on cultural of the country, inculcating enriched academic curricula targeting artistic development, encouraging cross cultural exchange and many more. A strong step in this direction will be generating intergenerational awareness as the youth of today will be future's torch bearer.

The government of Qatar should work to establish a single window services to the tourists which can provide them with all information related to arrival, visa facilities, custom forms and other formalities which they might require to fulfill. This should be specially done for those tourists who are eligible for visa on arrival or visa waiver program. The government of Qatar should be approachable for the tourists and open for their recommendations. The government can put up suggestion boxes in various public places like airports and tourists centers where international tourists can write about their complains and suggestions. This step can make the government offices approachable to the general tourists. The tourists can feel open to share their experiences, opinions, suggestions and complains. This can help in improving customer satisfaction and promote customer loyalty.

\section{CONCLUSIONS}

The purpose of this study is to examine the push and pull factors of tourists visit; their motivation and the activities carry out at the destination. This study explore to understand what comprises tourists are satisfied to transmit their positive experience to third persons as well as 
repeating their visit to Qatar. Push and pull factors are the effective tools to explain and predict destination satisfaction and return intention of them. Therefore, business organizations working in the tourism sector in in general should take into account the essential roles of push and pull factors, in order to understand and respond tourists' demands and expectations when they travel to Qatar. The results of this research can be used as valuable and accurate information for destination marketers and managers to implement strategies and plans, to not only attract more potential visitors, but also enhance their destination satisfaction and encourage them to re-visit to Qatar in the near future.

\section{REFERENCES}

[1] Adel H. Nikjoo., \& Mahmoud Ketabi. The role of push and pull factors in the way tourists choose their destination, Anatolia. 26(4), 2015, pp 588-597.

[2] Beh, A., \& Bruyerbe, B.L, Segmentation by Visitor Motivation in Three Kenyan National Reserves. Tourism Management. 28 (6), 2007, pp 1464-1471.

[3] Bideci, M., \& Albayrak, T, Motivations of the Russian and German tourists visiting pilgrimage site of Saint Nicholas Church. Tourism Management Perspectives 18, 2016, pp $10-13$

[4] C.N.Lai, Yu, T.K., \& J.K. Kuo, Social Behavior and Personality: An International Journal, 38(4), 2010, pp 509-514..

[5] Caber, M., \& Albayrak, T, Push or pull? Identifying rock climbing tourists' motivations, Tourism Management, 55, 2016, pp 74-84.

[6] Deichmann, J.I., \& Frempong, F, International Tourism in Ghana: A Survey Analysis of Traveler Motivations and Perceptions. Journal of Hospitality and Tourism Management. 29, 2016, pp 176- 183.

[7] Lam, T., \& Hsu, C.H.C, Predicting behavioural intention of choosing a travel destination. Tourism Management. 27(4), 2006, pp 589-599.

[8] Lam, T., Hsu, \& C.H.C, Predicting behavioral intention of choosing a travel destination. Tourism Management. 27(4), 2006, pp 589-599.

[9] Laws, E, Tourist Destination Management: Issues, Analysis and Policies. London, Routledge, 1995

[10] Leong, A. M. W., Yeh, S. S., Hsiao, Y. C., \& Huan, T. C. T, Nostalgia as travel motivation and its impact on tourists' loyalty. Journal of Business Research. 68(1), 2015, pp 81-86.

[11] Mai Ngoc Khuong., \& Huynh Thi Thu Ha, The Influences of Push and Pull Factors on the International Leisure Tourists' Return Intention to Ho Chi Minh City, Vietnam - A Mediation Analysis of Destination Satisfaction. International Journal of Trade, Economics and Finance. 5(6). 2014, pp 490-496.

[12] March, R. G., \& Woodside, A. G, Tourism Behavior: Travelers' Decisions and Actions. CABI Publishing, Cambridge, 2005

[13] Naidoo P., Ramseook-Munhurrun P., Seebaluck NV., \& Janvier S, Investigating the motivation of baby boomers for adventure tourism. Procedia-Social and Behavioral Sciences. 175, 2015, pp 244-251.

[14] Neuman, W.L, Social Research Method: Qualitative and Quantitative Approach. $7^{\text {th }}$ Edition. Publishing as Allyn \& Bacon (In print of Pearson). 75 Arlington Street Suite 300, Boston, USA., 2011

[15] Papatheodorou, A, Managing Tourism Destinations, Northampton, Edward Elgar Publishers, 2006

[16] Qatar Tourism Authority (QTA), Annual Tourism Performance Report. Retrieved from: https://www.visitqatar.qa/binaries/content/assets/corporate/statistics/en/2017/2017-annualtourism-performance-report_v2.pdf, 2017 
Tourist Satisfaction: an Analysis of Push and Pull Factors - A Case of Qatar Tourism

[17] Qatar Tribune. Retrieved from http://www.qatar-tribune.com/news-details/id/109844

[18] Simková, E., \& Holzner, J, Motivation of tourism participants. Procedia - Social and Behavioral Sciences. 159, 2014, pp 660-664.

[19] Van Vuuren, C., \& Slabbert, E, Travel behaviour of tourists to a South African holiday resort. African Journal for Physical, Health Education, Recreation and Dance. 17(4:1), 2011, pp 694-707.

[20] Venkatesh, U, Leisure: Meaning and Impact on Leisure Travel Behavior. Journal of Services Research. 6 (1), 2006, pp 87-108.

[21] Watthanaklang, D. et.al, Measuring the motivation to ride bicycles for tourism through a comparison of tourist attractions. Transport policy, 52,2016, pp 153-163.

[22] Whang, H., Yong. S., \& Ko, E, Pop culture, destination images, and visit intentions: Theory and research on travel motivations of Chinese and Russian tourists. Journal of Business Research. 69(2), 2016, pp 631-641. 